\title{
Exploring Historic Buildings Using Virtual Reality
}

\author{
Wei Zhang \\ 46th Floor, East Tower, Tianying Plaza, Tianhe District, Guangzhou, Guangdong, China \\ itsweizhang@outlook.com
}

\begin{abstract}
Virtual reality (VR) is an engaging feature that enables individuals to virtually interact within constructed settings and encounter them on a human scale using digital technology. For more than twenty years, virtual heritage (VH) capabilities have been a hot study topic among archaeologists and historians. Virtual legacy projects, with the exception of those created for the entertainment business, are mostly created by academics and researchers. Owing to their disorganized form and dearth of opportunity to reconnoiter within and around the environment, archaeological artifacts, pictures, drawings, textural records, and other materials fail to generate a comprehensive image of the vanished structure in our minds. These virtual legacy drives are basically worried about the 'Interaction' or the 'Items' (Virtual Reality frameworks), however they overlook the end-clients, or 'Individuals' who will use the framework. Humans are cultural beings with distinct cultural and demographic characteristics, therefore cultural interpretation, appraisal, and response are all subjective. To various individuals, different cultural environments have distinct meanings. As a result, in order to successfully teach about the past, it is critical to establish what end-user welfares are in a virtual historical setting. The goal of this study is to learn about users' experiences when a first-person shooter is used. The museum's visitors are shown a virtual reality-based reconstruction of a long-lost structure. This is a qualitative study interested in digitally rebuilding a lost structure utilizing museum resources and understanding the viewpoint of end-users (museum visitors) using Head Mounted Display-based first-person virtual heritage contexts in the presented work. The findings revealed significant design aspects for first-person virtual heritage settings, as well as qualities of historical and cultural knowledge that are critical for heritage learning in a first-person VH environment.
\end{abstract}

Keywords: VR (Virtual Reality), VH (Virtual Heritage), Two Dimensional, Three-Dimensional, Augmented Reality

\section{INTRODUCTION}

Previous research has shown that recreating a reallife situation is more effective as a learning technique than reading or seeing displays. Virtual Reality-based cultural heritage technology may be used to supplement traditional teaching methods[1]. Nonetheless, it is important to keep end-clients affianced with such computerized technologies to deliver a fruitful VR-based learning instrument for lost noteworthy constructions. Accordingly, figuring out what the end-client safeties are in a VR-based erudition for lost noteworthy designs is basic [2]. The interests of end-clients shift broadly relying upon their social setting, information on the particular structure, related knowledge with advanced advances, age, specialized capacities, learning limit, intellectual abilities, etc [3]. Thus, a nonstop evaluation of end-client interests is needed to figure out what they would need to encounter in Virtual Heritage settings.
End-user interests in virtual Heritage settings ought to be assessed consistently to help plan a more comprehensive informative instrument.

Virtual reality is a common method of simulating the actual world. In addition, virtual reality technology has greatly aided teaching in the constructed environment. Karlsson (2013) examined how the fast-rising deployment of virtual reality technology has benefitted built environment education. There have been various attempts in the past to build Virtual Heritage applications, and academics have generally agreed that Virtual Reality-based heritage tools are successful as an educational tool. Virtual heritage initiatives have mostly focused on innovative methods of reproducing history and the built environment in the virtual world during the last $10-15$ years [4].

These initiatives are primarily concerned with the 'product' and 'process,' but ignore the 'people,' i.e. the 
end-user. The method is concerned with the virtual reconstruction of cultural heritage, while the result is concerned with the virtual reality system. The most crucial aspect in creating a successful virtual heritage setting for teaching about the past is 'people.' However, researchers often overlook this feature, most likely because the product stays within the scope of study and academia. It is important to highlight that Digital Heritage apps are designed with the end-user in mind. In the VH environment, it's also unclear what an end-user requires. Physical and cultural factors, impact the users' experience in a virtual heritage setting. For example, one user may consider an artifact to be essential while another does not. Humans are cultural creatures, and differences in cultural and demographical backgrounds may influence how a cultural item is seen and interpreted. There has been relatively little study done in the past to investigate the aspects that contribute to cultural heritage learning among users of $\mathrm{VH}$ settings. As a result, enduser interests in virtual heritage learning environments ought be investigated.

The preferences of end-users vary widely depending on their cultural background, knowledge of the specific building, prior experience with digital technologies, age, technical abilities, learning capacity, cognitive skills, and so on. As a result, a continual assessment of end-user interests is required to determine what they would want to experience in Virtual Heritage settings. End-user interests in virtual heritage settings should be evaluated on a regular basis to assist design a more inclusive instructional tool. The issues that the present study is attempting to solve include: Inadequate resources to comprehend aspects in first-person virtual heritage settings from the standpoint of individuals.

The primary goal of this study is to look at end-users' experiences with a Virtual Reality-based pragmatic acquaintance tool and to discover the aspects that contribute to their cultural knowledge in a first-person virtual heritage setting.

The efficacy of the Virtual Reality system will not be investigated in this study. However, it tries to figure out what elements influence the end-users' learning experience in a first-person $\mathrm{VH}$ environment. Furthermore, the VR system used for this study will not be used to measure the user's capacity to acquire and retain information.

\section{OVERVIEW}

\subsection{Virtual Reality}

Virtual reality (VR) first surfaced in the guise of stereo head-mounted displays (HMDs), tracking, and graphics roughly half a century ago. Virtual reality technology has now caught the eye of everyone including scientists, academics, academicians, and business leaders have praised this game-changing technology [5] Virtual reality tries to mimic a certain behavior in a living thing. Simulations are interactive learning aids that simulate real-world scenarios [6].

Simulations may help to encourage the cost-effective implementation of processes and procedures that would otherwise be too costly in the real world. Recreations are important because they allow individuals to practice and learn abilities that would else be highly dangerous to do in the real world [7].

\subsection{The Use of Virtual Reality in Heritage Education}

Virtual heritage $(\mathrm{VH})$ is the process of using 3D models and virtual reality technologies to create historically and culturally important locations and artefacts [8]. The mix of computer-generated reality innovation with virtual reality technology with historical and cultural heritage information is known as virtual heritage [9]. Virtual legacy, as indicated by Abdelmonem (2017), is an intuitive innovation that tries to turn the experience of noteworthy designs, social scenes, and metropolitan spots into a vivid commitment for normal individuals [10]. Virtual Heritage was initially utilized during the 1990s and mid-2000s, with archeologists being the essential clients [4]. Computer generated reality innovation is progressively being utilized in galleries and other social legacy settings to advance government funded training [11]. Lately, the capability of perception innovations in the Cultural Heritage region has started to be figured it out [12]. In general, $\mathrm{VH}$ technologies may assist relive the past by providing a cost-effective means to go to and study lost historic sites. Virtual heritage settings are designed to preserve, replicate, and display history using cutting-edge technology. A virtual museum is a digital version of a real museum with the same goal as a real museum and, as a result, to impart information to visitors via casual education [13].

\section{METHODOLOGY}

The goal of the study is to learn about the end users' experiences while reconnoitering the virtually reconstructed model in order to determine the aspects that influence their cultural learning in VH contexts. A missing historic structure has been located in order to meet the study goal. The structure was at Chappell Hill, Texas.

Soule University and the Chappell Hill Female College, both Methodist schools of higher learning, were located at Chappell Hill. The state established Soule University in 1856, and work on its three-story edifice started in 1858. During the Civil War, the school was destroyed and the construction was repurposed as a Confederate healing clinic. After the conflict, the 
foundation returned and worked until 1873, when the Methodist Church set up Southwestern University in Georgetown, Texas. Notwithstanding the way that the school had lost its Methodist alliance at that point, it kept on working as Soule College until 1887, when it was in the long run shut. The construction was destroyed in 1911. Occupants of Chappell Hill acknowledged around fifty years prior that the little local area actually had its enchanting nineteenth century appearance and feel, however that the maturing system was having its cost. They founded the Chappell Hill Historical Society in order to safeguard the most notable structures and began collecting them. Four historic buildings are now owned and maintained by the Society, one of which has been transformed into a museum. This museum receives around 200 visitors each month, and one of the rooms depicts Soule University.

\subsection{Experiential Model Based on Virtual Reality Development}

Textual and archaeological data are required to produce a virtual recreation of a vanished structure. Textual evidence consists of written materials such as statistical reports and literary works, whereas archaeological evidence consists of the actual relics of the past. In order to offer accurate background information, this evidence is critical in the virtual reconstruction process [14].

The researcher virtually toured Chappell Hill, Texas in order to establish an accurate 3D model of the Soule University Building, as they were an important part of collecting information, comprehension the background, and envisioning what was in venue before the Soule University building was ripped down.

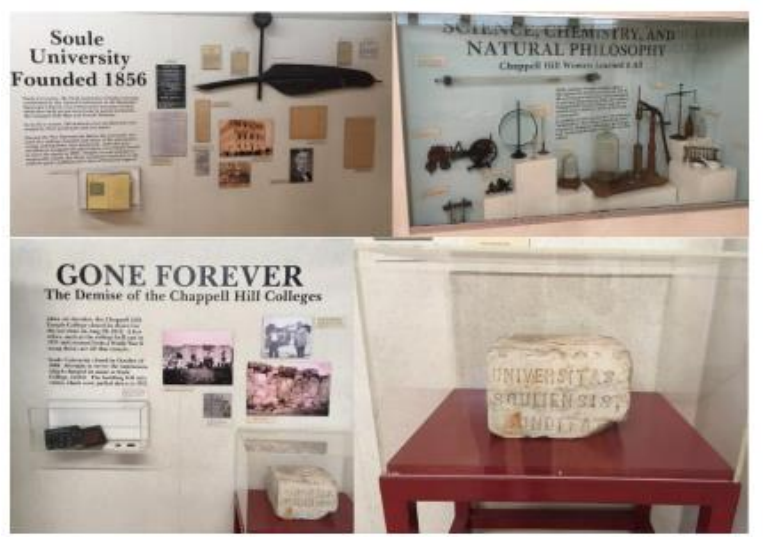

Figure 1 Materials available in the Chappell Hill Museum

An exhaustive study of the examined images, drawings, textual documents, and artifacts was used to gather the information needed for the $3 \mathrm{D}$ reconstruction effort. We learned about the materials used in the construction of the Soule University Structure by looking at the textual documentation in the museum. We also learned about the number of classrooms on each level, various functional areas within the building, and the building's size and built-up area. The architectural plan of the building interior, size, style, and number of doors and windows in each floor were all disclosed through a detailed analysis of the construction specification provided by Soule University to contractors and builders in 1859. The images, drawings, and artifacts, like the literature study, were highly important since they enabled us to envision and examine all of the elements of the building outside, particularly those connected to the architectural style and texture.

The preparation of $2 \mathrm{D}$ designs for each floor of the building is the next phase in the $3 \mathrm{D}$ reconstruction process once all necessary information about building measurements, architectural style, building components, materials, and texture has been gathered. The AutoCAD $2 \mathrm{D}$ designs were used to load into $3 \mathrm{D}$ modeling software in order to produce 3D geometry. Because the actual interior design of the building could not be determined, assumptions were established dependent on the descriptions of the structural system.

The dimensions of the classrooms, the position of the staircases, the riser height and tread depth of the stairs, the width of the hallway, the placement of windows and doors, and other assumptions were used to build the drawings. The program AutoCAD was used to create floor designs for the building based on assumptions and textual documents. AutoCAD was selected because of its ease of use and versatility in drafting 2D designs quickly and precisely, with no further training required. Following the development of the 2D blueprints, a 3D model was created using the program Archicad for the first examination of the design.

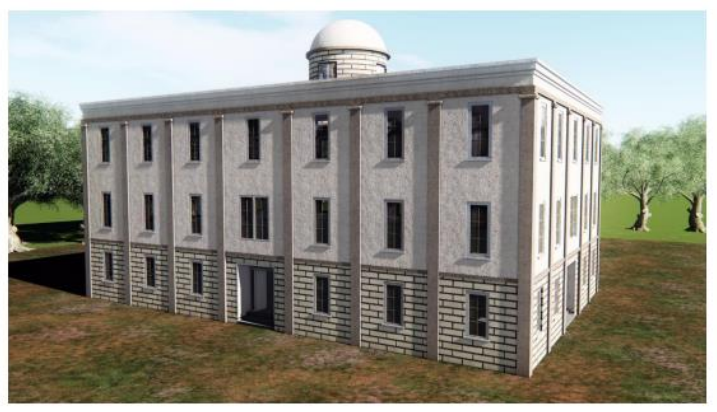

Figure 2 The Archicad 3D model reviewed in Twinmotion 


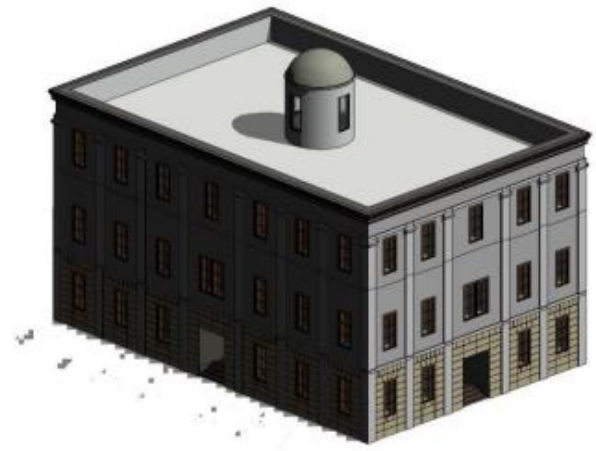

Figure 3 Final 3D Model of Soule University developed in Autodesk Revit

\subsection{End-User Experience Evaluation}

The significant objective of this review is to look into end-users' encounters utilizing a Virtual Reality-based experiential model instrument to sort out what they need to find in the VR arrangement and how it very well may be upgraded to keep them intrigued by such a virtual environment. It is basic to assess human connections with the proposed Virtual Reality-based learning instrument for the mislaid structure and assemble remarks on their understanding for the reasons for this review. Subjective examination approach is used to survey the delivered learning technique. Phenomenological analysis will be employed as a qualitative research approach in this study. Understanding user viewpoints as one experiences and understands a sensation, program, connection, event, and so on is the goal of phenomenological analysis. The participant's comments would be utilized to determine end-user interests as well as the benefits and drawbacks of the VR-based learning tool. A typical sample size for a phenomenological investigation, is 5 to 25 individuals. As part of this research, 10 museum visitors were interviewed.

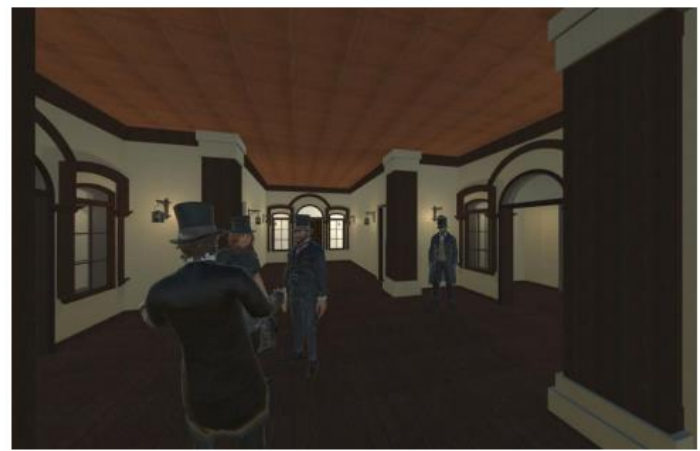

Figure 4 VR Model of Soule University featuring Virtual Avatars

The interviews were aimed to learn about the participants' attitudes regarding adopting a VR-based Experiential Learning tool. By providing open-ended questions to the participants, the interviews were planned to be highly flexible and casual, enabling them to share their ideas on the established learning approach for vanished structures. The researcher found similar motifs from the transcribed data throughout the data analysis phase. The merits and drawbacks of a VR-based learning tool, as well as suggestions and changes that end users would want to see in a VR-based learning of lost historic structures, are the focus of this study.

\section{DISCUSSION}

The vital outcomes according to the exploration are introduced in this piece of the report. The discoveries in this review are exclusively founded on the criticism, remarks, perspectives, and concerns communicated by members during the preliminary. The outcomes uncovered an abundance of data with respect to important plan angles for first-individual virtual legacy settings, just as physiognomies of chronicled and social evidence that are basic for legacy learning in a firstindividual VH climate. The findings are coordinated by the classes and subjects found during information investigation.

Incorporation of tangible cultural and historical data: During the investigation, majority of the participants anticipated or want to see tangible cultural material when investigating Soule University's VH model. Architectural characteristics, artefacts, archaeological remnants, surrounding environment, inhabited spaces (with furniture), people's clothes, and other tangible cultural knowledge piqued participants' attention.

Most of users looked to see the practically dynamic submits in request to consider and grasp the populace and specific exercises that happened inside the evaporated Soule University.

Vivid experience: A couple of members said that they wished to take part in discussions with virtual symbols, homeroom exercises, and be conspicuous by the characters in the virtual world also. A few clients have said that they need their essence inside the structure to be distinguished so they might draw in with the virtual characters while visiting the structure. Many individuals communicated stresses over how to go about inside the design. A few participants favored a directed visit, while others needed to meander about the office all alone. Accordingly, the framework should have options for both self-coordinated and directed visits so clients might pick their favored strategy. The directions for controlling the navigation tool were also a major source of anxiety among the participants (gamepad). Despite the fact that the participants were taught how to use the controller, several of them requested particular navigation directions on the screen. Some participants demanded signs and labeling, while others wanted to be able to teleport to various levels and places without having to ascend the stairs or retrace their steps. A few people 
suggested that there be shortcut options on the interface to click and travel to other levels and locations.

Realism: Nearly every single participant said that they enjoy the 1st person virtual reality-based education of the mislaid building because it allows them to envision the structure and explore it on a human size. They also praised the high quality of the images, which allowed them to feel the cultural presence. The viewpoint of users in a virtual heritage environment varies depending on their topic knowledge and technological skill. As a result, future research might concentrate on determining the user needs and interests for each of the user groups defined by Walsh et al (2016) [15]. This might aid in the development and evaluation of virtual heritage systems from the standpoint of various human players.

\section{CONCLUSION}

This study looks at the viewpoints of end-users in a 1st person virtual heritage milieu to see what characteristics and influences help them learn more about their culture. The results suggest that while creating VH applications, a mix of information design, content delivery, user experience, and guidance system should be addressed. End-users' cultural learning experience might be enhanced by creating a virtual heritage milieu that incorporates the variables and components described in this stud. These components and aspects might be utilized as design guiding principle for the creation of virtual heritage settings based on historic structures that have been lost. There are eight main types of users that utilize digital heritage settings. The subject knowledge and technical competence of the users in such areas are categorized as Low, Medium, and High, respectively. The reasons for wanting to learn about the past varies as well. Users' perspectives in a virtual heritage environment vary depending on their topic knowledge and technological skill. As a result, future research might concentrate on determining the user needs and interests for each of the user groups defined by Walsh et al (2016) [15]. This might aid in the development and evaluation of virtual heritage systems from the standpoint of various human players.

\section{ACKNOWLEDGMENT}

I'd want to express my gratitude to the following individuals who have helped me not just during this project, but also during my studies. First and foremost, I'd want to thank my adviser for his constant support, advice, and direction during this research effort. My heartfelt gratitude goes out to my friends, as well as the Department faculty and staff, for making my stay at this institution so unforgettable. I'd also want to thank the members of the Chappell Hill Historical Society Museum for their assistance with the data collecting. Finally, I'd want to express my gratitude to my parents for their unwavering support.

\section{REFERENCES}

[1] Mikropoulos, T. A., \& Natsis, A. (2011). Educational virtual environments: A ten-year review of empirical research (1999-2009). Computers \& Education, 56(3), 769-780.

[2] Lord, B. (2007). What is museum-based learning. The Manual of Museum Learning. AltaMira Press, Lanham, 13-19.

[3] Jose, S., Patrick, P. G., \& Moseley, C. (2017). Experiential learning theory: the importance of outdoor classrooms in environmental education. International Journal of Science Education, Part B, 7(3), 269-284.

[4] Bretz, E. (2017). Exploring how one virtual heritage application connects users to historical content: a user experience case study. (Master of Arts), Ball State University, Muncie, IN.

[5] Slater, M., \& Sanchez-Vives, M. V. (2016). Enhancing our lives with immersive virtual reality. Frontiers in Robotics and AI, 3, 74

[6] Merchant, Z., Goetz, E. T., Cifuentes, L., KeeneyKennicutt, W., \& Davis, T. J. (2014). Effectiveness of virtual reality-based instruction on students' learning outcomes in K-12 and higher education: A meta-analysis. Computers \& Education, 70, 29-40.

[7] Champion, E. (2010). Game-Style Interaction. In Playing with the Past: Springer.

[8] Wright, T., \& Madey, G. (2008). A survey of collaborative virtual environment technologies. University of Notre Dame-USA, Tech. Rep, 1-16.

[9] Addison, A. C. (2000). Emerging trends in virtual heritage. IEEE MultiMedia, 7(2), 22-25.

[10] Abdelmonem, M. G. (2017). Reliving Past Architecture: Virtual heritage and the reproduction of history through creative modes of heritage visualisation. Paper presented at the International Conference on Trends in Architecture and Construction

[11] Pujol-Tost, L. (2017). "3d· Cod": A New Methodology for the design of Virtual RealityMediated experiences in digital Archeology. Frontiers in Digital Humanities, 4, 16.

[12] Dagnino, F. M., Pozzi, F., Cozzani, G., \& Bernava, L. (2017). Using Serious Games for Intangible Cultural Heritage (ICH) Education: A Journey into the Canto a Tenore Singing Style. Paper presented at the VISIGRAPP (5: VISAPP).

[13] Rahim, N., Wook, T. S. M. T., \& Zin, N. A. M. (2017). Analysis on user Interaction in Virtual 
Heritage: Virtual Museum Environment. Indian Journal of Science and Technology, 10(48).

[14] Karlsson, C. (2013). Visualizing Archaeology-with Virtual Reality tools. (Masters in Historical Archaeology), Lund University, Lund, Sweden.

[15] Walsh, D., Clough, P., \& Foster, J. (2016). User Categories for Digital Cultural Heritage. Paper presented at the Proceedings of 1st International Workshop on Accessing Cultural Heritage at Scale, Newark, NJ, USA. 